\title{
Análise da dispersão de ondas de superfície do tipo Rayleigh na Província Borbo- rema, NE Brasil.
}

Rosana Maria do Nascimento*1, Aderson Farias do Nascimento ${ }^{1}$, Joaquim Mendes Ferreira ${ }^{1}$, Marcelo Assumpção ${ }^{2}$

1-Programa de Pós-Graduação em Geodinâmica e Geofísica, Universidade Federal do Rio Grande do Norte, Natal/RN Brasil.

2-Departamento de Geofísica, Universidade de São Paulo, São Paulo, Brasil.

Copyright 2010, SBGf - Sociedade Brasileira de Geofísica Este texto foi preparado para a apresentação no IV Simpósio Brasileiro de Geofísica, Brasília, 14 a 17 de novembro de 2010. Seu conteúdo foi revisado pelo Comitê Técnico do IV SimBGf, mas não necessariamente representa a opinião da SBGf ou de seus associados. É proibida a reprodução total ou parcial deste material para propósitos comerciais sem prévia autorização da SBGf.

\section{RESUMO}

Na Província Borborema, NE do Brasil, estudamos o comportamento da velocidade da onda $S$ com a profundidade na crosta, através da característica de dispersão das ondas de superfície, utilizando o método interestação. O método Inter-Estação, nos ajuda a estimar como a velocidade da onda $S$ se comporta na região entre duas ou mais estações. As inversões das curvas de dispersão são realizadas com ondas Rayleigh. Usamos também o conhecimento da profundidade da Moho, como vínculo na inversão. Com diferentes parametrizações de modelos para a inversão, nossos resultados foram de perfis médios de velocidade de onda $S$ muito parecidos. Em particular, o perfil que possui a Bacia Potiguar no percurso inter-estação (duas estações), apresenta baixas velocidades na crosta e os perfis com três estações identificam a profundidade da Moho na região.

\section{INTRODUÇÃO}

A Província Borborema, situa-se na região Setentrional do Nordeste Brasileiro e tem sido estudada através de muitos métodos geofísicos: tomografia de ondas de superfície (Vilar 2004), métodos potencias (Castro et al., 1998; Oliveira, 2008) e função do receptor (Novo Barbosa, 2008). Todos esses trabalhos têm a finalidade de entender a estrutura interna da província, com o intuito de caracterizar a geologia e a evolução tectônica de cada região.

Com o objetivo de adicionar mais um estudo geofísico na região, estimamos o comportamento da velocidade da onda S com a profundidade na província Borborema. Para isto, utilizamos a dispersão de ondas de superfície entre duas e três estações (método inter-estação). A curva de dispersão nos mostra a velocidade de grupo ou fase das ondas para vários períodos. De posse das curvas, podemos invertê-las e obter o perfil da velocidade da onda S com a profundidade, uma vez que as ondas de superfície são sensíveis à variação da onda $S$. As curvas de dispersão inter-estações foram calculadas pela Técnica de Filtragem Múltipla (Multiple Filter Technique, MFT) (Dziewonski et al. 1969), que calcula as variações da amplitude de um sinal em função da velocidade e do período da onda. A inversão das curvas de dispersão para a determinação do perfil das velocidades de onda S com a profundidade será realizada utilizando os programas computacionais do pacote do (Herrmann, 2002).

\section{DISPERSÃO DE ONDAS DE SUPERFÍCIE}

A dispersão de ondas ocorre quando diferentes componentes de frequências se propagam com diferentes velocidades. A dispersão de ondas de superfície é caracterizada por longos períodos das ondas que chegam a uma profundidade maior e curtos períodos das que chegam a uma profundidade menor. Ou seja, ondas com períodos diferentes são sensíveis às estruturas à profundidades diferentes.

Nos estudos das ondas de superfície, a grande meta é determinar as velocidades de fase/grupo para um determinado número de períodos. Isto pode ser feito de duas maneiras: i) usando o registro em uma única estação, conhecendo as características da fonte e ii) usando duas ou mais de estações (inter-estações). Em nossa análise das ondas de superfície, usamos as velocidades de fase inter-estação.

Para ondas de superfície $u(x, t)$ observadas por duas estações (Snoke \& James, 1997; Meijian An, 2004;

Darbyshire, 2005;), nas posições $x_{1}$ e $x_{2}$, a diferença das fases $(\phi)$ entre as duas estações:

$$
\Delta \phi(\omega)=\phi_{2}(\omega)-\phi_{1}(\omega) \pm 2 n \pi
$$

onde $2 n \pi$ é incluído para levar em conta a ambiguidade da fase. Desde que a dependência com a distância $x$ de cada componente senoidal seja $e^{i k x}$, a mudança da fase na propagação de $x_{1}$ a $x_{2}$ :

$$
\Delta \phi(\omega)=k\left(x_{2}-x_{1}\right)=\frac{\omega}{c(\omega)}\left(x_{2}-x_{1}\right)
$$

Assim, a velocidade de fase $c(\omega)$ entre duas estações pode ser expressa por:

$$
c(\omega)=\frac{\omega\left(x_{2}-x_{1}\right)}{\phi_{2}-\phi_{1} \pm 2 n \pi}
$$

Dessa forma, a determinação de velocidade de fase interestações não depende do mecanismo focal do terremoto. Para o cálculo da curva de dispersão, utilizamos a técnica de filtragem múltipla (Dziewonski et al., 1969), que 
é usada para estudar as variações de amplitude de um sinal em função da velocidade e do período, medindo assim as velocidades de grupo. A função da janela do filtro Gaussiano pode ser escrita como (Dziewonski et al., 1969; Herrin \& Goforth, 1977):

$$
H_{n}(\omega)=e^{-\alpha\left(\frac{\omega-\omega_{n}}{\omega_{n}}\right)^{2}}
$$

onde $\omega_{n}$ é a frequência central do filtro e $\alpha$ é um parâmetro de largura do filtro que controla a resolução da medida da velocidade de grupo (Bhattacharya, 1983). Para realizar a inversão da dispersão de ondas de superfície, utilizamos o programa computacional Surf96 pertencente ao pacote do Herrmann \& Ammon (2002). O Surf96 usa o método de inversão linearizada iterativa a partir de um modelo inicial, onde a representação das velocidades de fase como função das velocidades da onda S é:

$$
C(T)=f\left(\beta_{i}\right)
$$

No nosso método de inversão incorporamos o vínculo de suavidade, supondo a priori, que a interface entre cada camada varia espacialmente de forma suave. Por outro lado, analisar um perfil sem suavidade pode nos indicar onde o perfil mostra mais instabilidades e assim talvez encontrar descontinuidades. O termo da suavidade é acrescentado ao funcional:

$$
f=R_{u}+\sigma R_{\text {suave }}
$$

Onde $R_{u}$ é o ajuste das velocidades de fase $\left(C(T)_{\text {obs }}\right.$ $\left.C(T)_{\text {teor }}\right)^{2}, R_{\text {suave }}$ é a suavidade e $\sigma$ é o peso que se dá a suavidade.

Neste trabalho, o modelo inicial possui diferentes parametrizações, no que diz respeito as espessuras das camadas e a suavidade: i) Camadas com diferentes espessuras suavizadas; ii) Camadas com diferentes espessuras sem suavização; iii) Camadas com espessuras fixas suavizadas; iv) Camadas com diferentes espessuras suavizadas com a Moho fixa.

\section{SELEÇÃO DE DADOS}

Os eventos que utilizamos nesse trabalho, foram registrados por estações Banda larga, pertencentes ao projeto Milênio (Estudos Geofísicos e Tectônicos na Província Borborema) - CNPq, instaladas ao longo da Província Borborema. Usamos também a estação RCBR (instalada mediante um convênio entre a UFRN e o USGS (Serviço geológico dos EEUU) ).

Os dados selecionados são entre os anos de 2007 e 2010. Ao todo estão sendo usados seis eventos com magnitude acima de $5.0 M_{W}$ e profundidade até $40 \mathrm{~km}$. As ondas de superfície de eventos dessa magnitude apresentaram curvas de dispersão ideais para o método. Quanto a profundidade, recomenda-se eventos rasos pois estes geram mais ondas de superfície. Neste trabalho, o caminho de círculo máximo para os eventos inter-estações não deve ultrapassar $10^{\circ}$ entre o caminho de círculo máximo entre as estações (para duas estações), pois a trajetória das ondas devem ser as mesmas para as duas estações. Os pares de estações para o cálculo das curvas de dispersão inter-estações são SBBR-OCBR, SBBR-PFBR, SBBR-RCBR, PFBR-SABR e PFBR-SLBR e para três estações utilizamos SBBROCBR-RCBR e SBBR-OCBR-PFBR, mostrados na figura 1. Na figura 2, mostramos um mapa completo com todos os epicentros usados no trabalho.

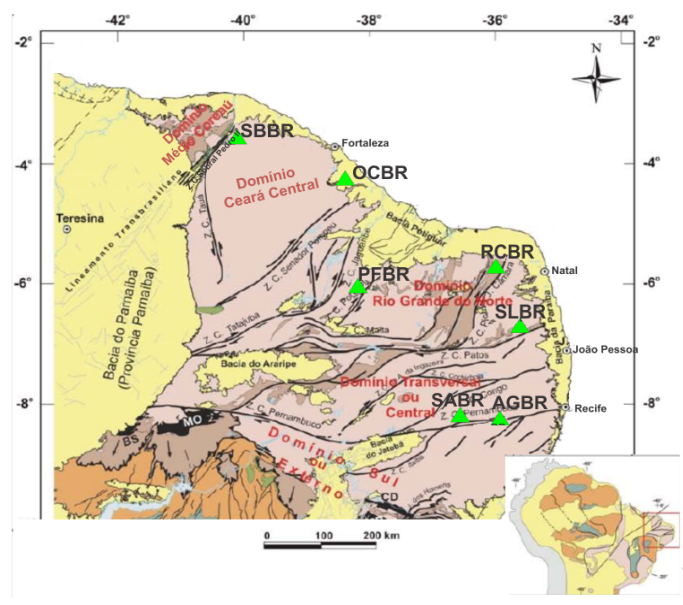

Figura 1: - Arranjo de estações na Província Borborema, os triângulos verdes são as estações do projeto Milênio e mais a estação RCBR. Figura baseada na cartografia de Bizzi e Vidotti, 2003.

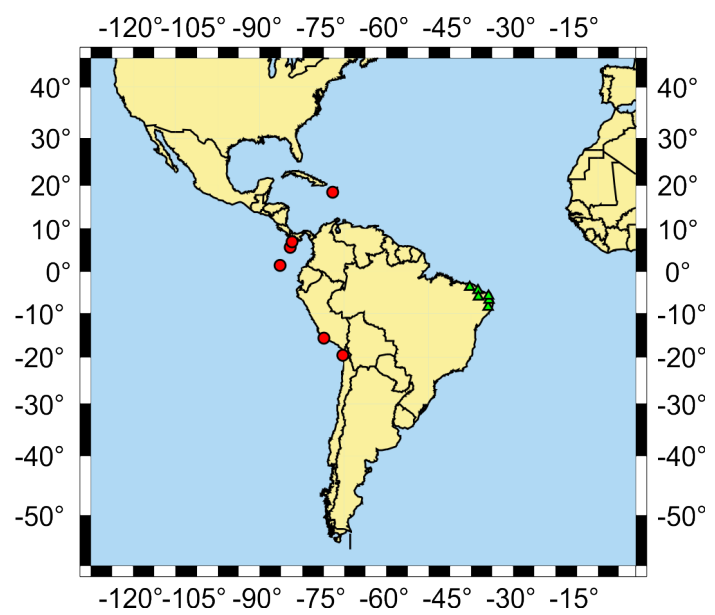

Figura 2: - Mapa com as estações BB e os 6 epicentros usados no trabalho.

\section{RESULTADOS}

Nossos resultados foram processados para ondas Rayleigh. Os perfis inter-estações com resultados mais significativos são SBBR-PFBR e SBBR-RCBR, para 3 estações acrescentamos OCBR. Na figura 1, quanto à geologia da região, podemos observar que entre as estações 
há muitas zonas de cisalhamentos, o que influencia nos resultados dos perfis. As figuras 6,7 e 8 , são respectivamente, as curvas de dispersão e os perfis dos pares SBBR-RCBR (evento do Haiti 12/01/2010, 5.9 $\mathrm{M}_{W}$ ), SBBR-PFBR (evento do Norte da Califórnia 10/01/2010, $6.5 M_{W}$ ) e os perfis com três estações. Os caminhos do raio dos dois eventos chegando nas estações são mostrados na figura 3.

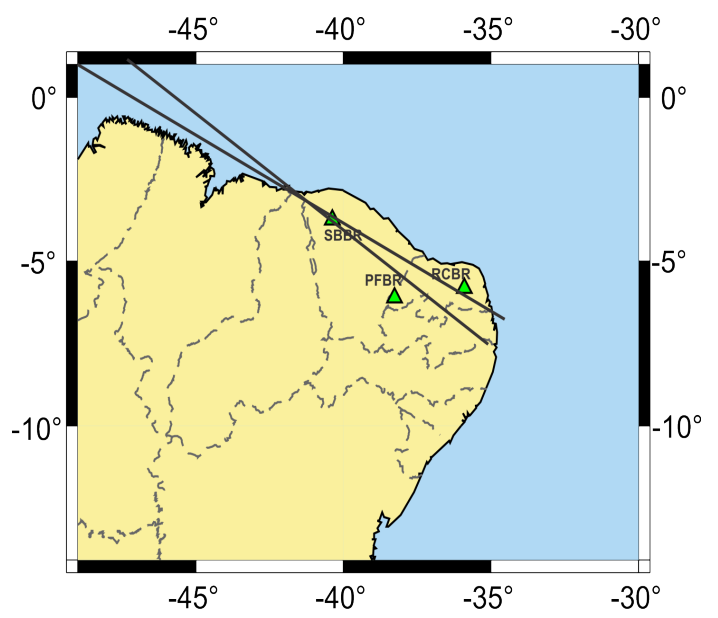

Figura 3: - Caminho do raios (linhas grossas da esquerda para a direita) dos eventos e a região do domínio Ceará Central e domínio Rio Grande do Norte, para os perfis SBBR-PFBR e SBBR-RCBR. Os triângulos verdes são as estações.

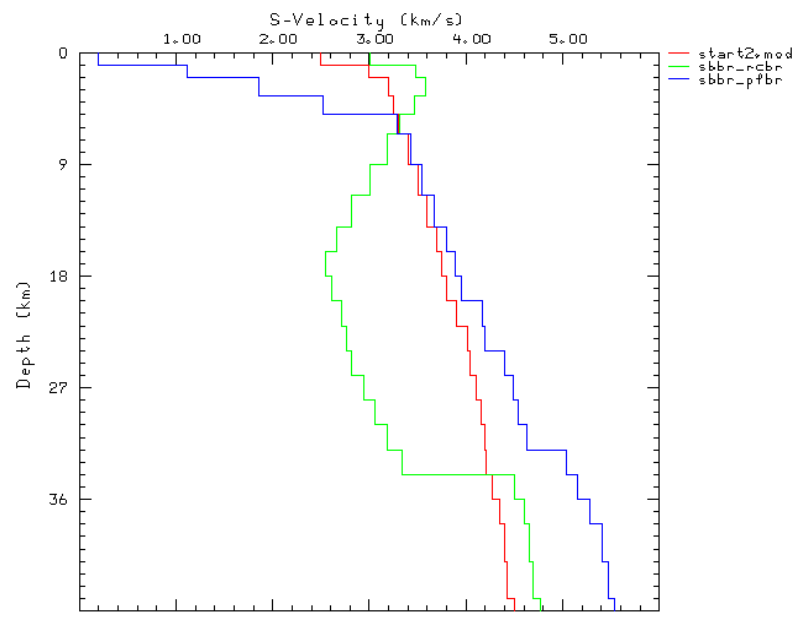

Figura 4: - perfis médios dos pares de estações usados no trabalho. start2.mod é o modelo inicial.

Os resultados da velocidade da onda $S$ para os perfis médios são comparados aos valores da velocidade da onda S esperados na crosta e no manto superior: 3.2 $\mathrm{km} / \mathrm{s}$ a $3.8 \mathrm{~km} / \mathrm{s}$ na crosta superior e $4.4 \mathrm{~km} / \mathrm{s}$ a $4.7 \mathrm{~km} / \mathrm{s}$ no manto superior (Shearer,1999; Aki \& Richards, 2002). Nos resultados do par SBBR-RCBR, há muitas variações no perfil e os dados são considerados confiáveis

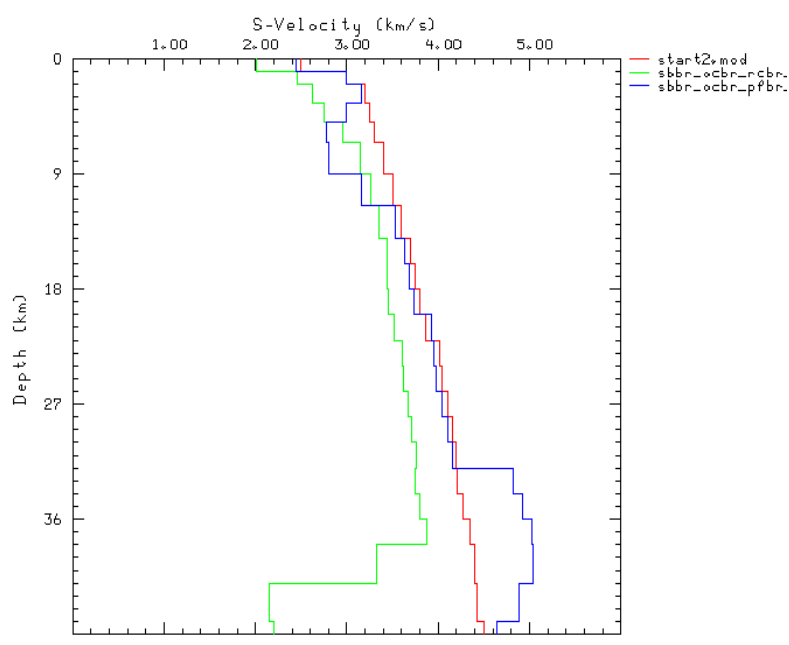

Figura 5: - perfis médios com três estações usados no trabalho. start2.mod é o modelo inicial.

até a Moho ( $34 \mathrm{~km}$ de profundidade), onde os valores da velocidade de $\mathrm{S}$ ainda são os esperados. Os perfis com três estações possuem menos variações na velocidade da onda $S$ do que os perfis com duas estações. Com o resultado de uma parametrização e muitas variações no perfil, podemos sugerir a existência de forte variação lateral no manto superior. O caminho de raio de um evento passa pela bacia potiguar, e por isso, pode ser que haja uma camada de baixa velocidade entre $\sim$ $12 \mathrm{~km}$ e a Moho.

\section{DISCUSSÃO E CONCLUSÕES}

A figura 4 e 5 mostram que os perfis médios de todos os pares possuem padrões similares de velocidade da onda S, aproximadamente no intervalo de $10 \mathrm{~km}$ a 24 $\mathrm{km}$. Comparando a figura 4 de perfis com duas estações e a figura 5 de perfis com três estações, conseguimos identificar a Moho aproximadamente na mesma profundidade nos dois tipos de perfis. A maioria dos perfis estão dentro do intervalo de velocidade esperado na crosta, com excessão de alguns valores dos perfis SBBR-PFBR e SBBR-RCBR. Até aproximadamente 10 $\mathrm{km}$ de profundidade, as velocidades da onda S são menores que $4 \mathrm{~km} / \mathrm{s}$ para todos os pares.

O perfil SBBR-RCBR difere muito dos outros perfis, isso se deve ao fato do percurso inter-estação possuir muitas estruturas diferentes, inclusive a Bacia Potiguar, provocando muitas variações nas velocidades da onda S. No perfil SBBR-OCBR-RCBR, que também inclui a Bacia Potiguar há menos variações nas velocidades da onda S. Integramos nossos resultados com os resultados de Função do Receptor e Gravimetria. As estimativas da função do receptor (Novo Barbosa, 2008), mostram que sob as estações SBBR, OCBR e RCBR a crosta é mais espessa do que sob as outras estações usadas nesse 
trabalho. Em nossos perfis, nos pares inter-estações SBBR-OCBR e SBBR-PFBR, observamos que nos primeiros $10 \mathrm{~km}$ as velocidades são mais baixas, o que indica que a crosta deve ser mais grossa, concordando assim com o resultado da função do receptor.

Quanto aos estudos de gravimetria, Oliveira (2008) afirma que na porção oeste do domínio Ceará Central (DCC) o padrão gravimétrico é muito complexo, isso sugere uma importante descontinuidade na crosta dessa região. Nossos resultados mostram que os perfis dos pares SBBR-OCBR e SBBR-PFBR, possuem muita variação da onda $S$ na crosta indicando instabilidades, o que pode implicar que exista forte variação lateral e portanto que as estruturas da crosta sejam diferentes.

Portanto, observamos que para os perfis com três estações, as variações da velocidade da onda S com a profundidade foram menores do que nos perfis com duas estações. Em ambos os perfis, com duas e três estações, a Moho é identificada praticamente a mesma profundidade.

\section{AGRADECIMENTOS}

Ao Projeto do Milênio (CNPq), Ao Instituto Nacional de Ciência e Tecnologia - Estudos Tectônicos (INCT-ET/CNPq). AFdN, JMF e MA agradecem ao CNPq pelas suas respectivas bolsas $P Q$.

\section{REFERÊNCIAS}

Almeida, F.FM., Brito Neves, B.B., Fuck, R.A., 1977. Províncias Estruturais Brasileiras. Atas VIII Simpósio de Geologia do Nordeste. Campina Grande, p.363-391.

Aki, K., \& Richards, P. G., 2002. Quantitative Seismology: Theory and Methods. W. H. Freeman and Company, San Francisco.

An, M., 2004. Estrutura Crustal da Bacia do Paraná com Inversão de Ondas de Superfície e Funções do Receptor. PhD tese, IAG, Universidade de São Paulo, São Paulo, Brazil.

An, M., Assumpção, M.S., 2005. Effect of lateral variation and model parameterization on surface wave dispersion inversion to estimate the average shallow structure in the Paran Basin. Jornal of Seismology., 9: 449.

Bizzi L.A. \& Vidotti R.M. 2003. Condicionamento do Magmatismo pós-Gondwana. In: Bizzi L.A., Schobbenhaus C., Vidotti R.M. \& Gonçalves, J.H. (orgs.). 2003. Geologia, tectônica e recursos minerais do Brasil: texto, mapas \& SIG. CPRM - Serviço Geológico do Brasil,Brasília p.335-361.

Castro, D.L; Medeiros, W .E.; Jardim de Sá, E.F.;Moreira,
J.A.M., 1998. Mapa gravimétrico do nordeste setentrional do Brasil e margem continental adjacente: interpretação com base na hipótese de isostasia. Revista Brasileira de Geofísica. 16 (2/3): 115-132.

Herrin, E., \& Goforth, T., 1977. Phase-matched filters: Application to the study of Rayleigh waves. Bull. Seism. Soc. Am., 67:1259-1275.

Herrmann, R. B., \& Ammon, C. J., 2002. Computer programs in seismology - surface waves, receiver functions and crustal structure. St. Louis University, St. Louis, MO. URL http://www.eas.slu.edu/People/RBHerrmann/Computer Programs.html.

Feng, M., 2004. Tomografia de Ondas de Superfície na América do Sul: Inversão Conjunta de Velocidade de Grupo e Forma de Onda. PhD tese, IAG, Universidade de São Paulo, São Paulo, Brazil.

Novo Barbosa, M.F., 2008. Estimativa de Espessura Crustal na Província Borborema (NE/Brasil) através de Função do Receptor. Dissertação de Mestrado, Programa de Pós Graduação em Geodinâmica e Geofísica, Universidade Federal do Rio Grande do Norte, p.10-11.

Oliveira, R.G., 2008. Arcabouço Geofísico, Isostasia e causas do magmatismo cenozóico da Província Borborema e de sua margem continental (Nordeste do Brasil). Tese de Doutorado, Programa de Pós Graduação em Geodinâmica e Geofísica, Universidade Federal do Rio Grande do Norte.

Shearer, P. M., 1999. Introduction to Seismology. Cambridge universtiy press.

Snoke, J. A., \& James, D. E., 1997. Lithospheric structure of the Chaco and Paran basins of South America from surface-wave inversion. J Geophys. Res., 102:29392951.

Snoke, J. A., \& Sambridge, M., 2002. Constraints on the $S$ wave velocity structure in a continental shield from surface wave data: Comparing linearized least squares inversion and the direct search neighbourhood algoritm. J. Geophys. Res.

Vilar, C. S., 2004. Estrutura Tridimensional da Onda S na Litosfera do Nordeste Brasileiro. Tese de Doutorado, Observatório Nacional, Rio de Janeiro, 258p. 

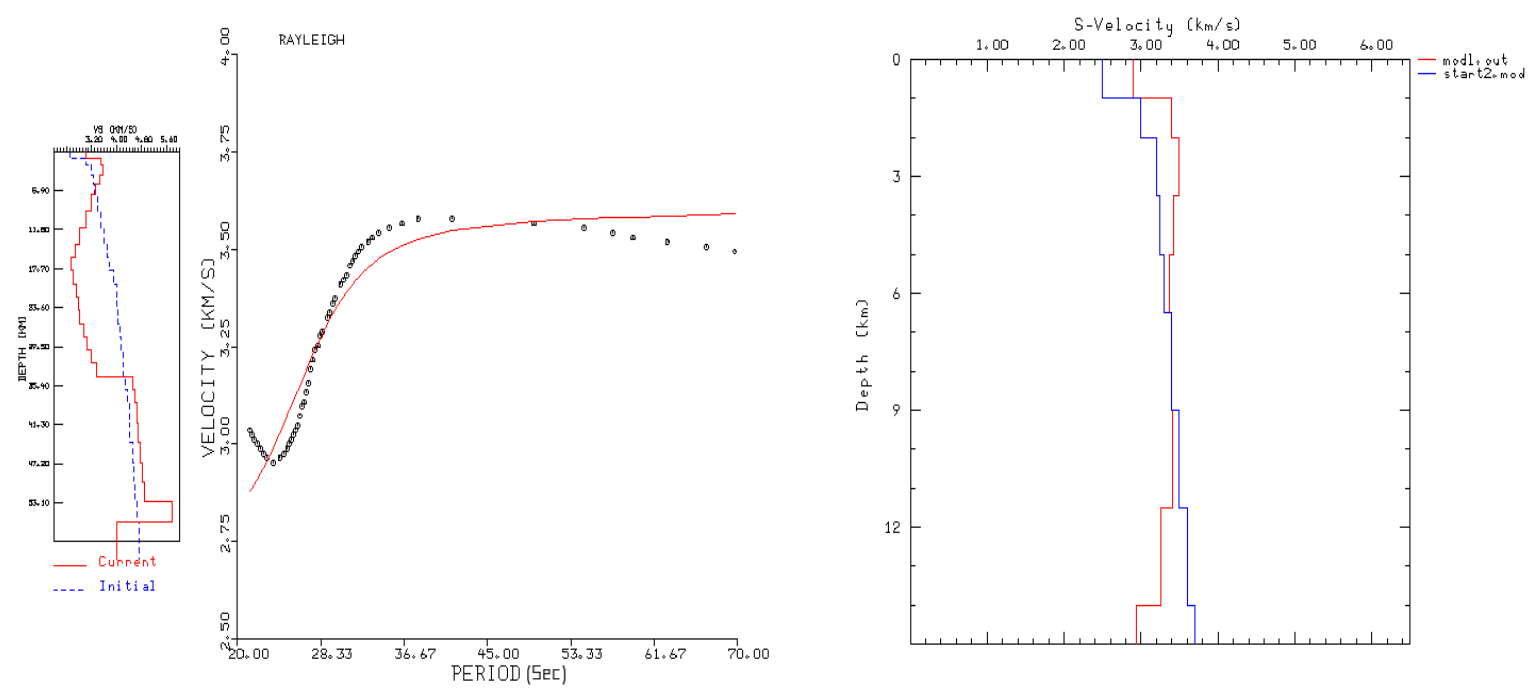

Figura 6: - Evento do Haiti. A esquerda, perfil e ajuste da curva de dispersão, ondas Love. O current é o resultado da inversão e initial é o modelo inicial. A direita, perfil da velocidade de onda S,ondas Love. O modl.out resultado da inversão e start2.mod é o modelo inicial.
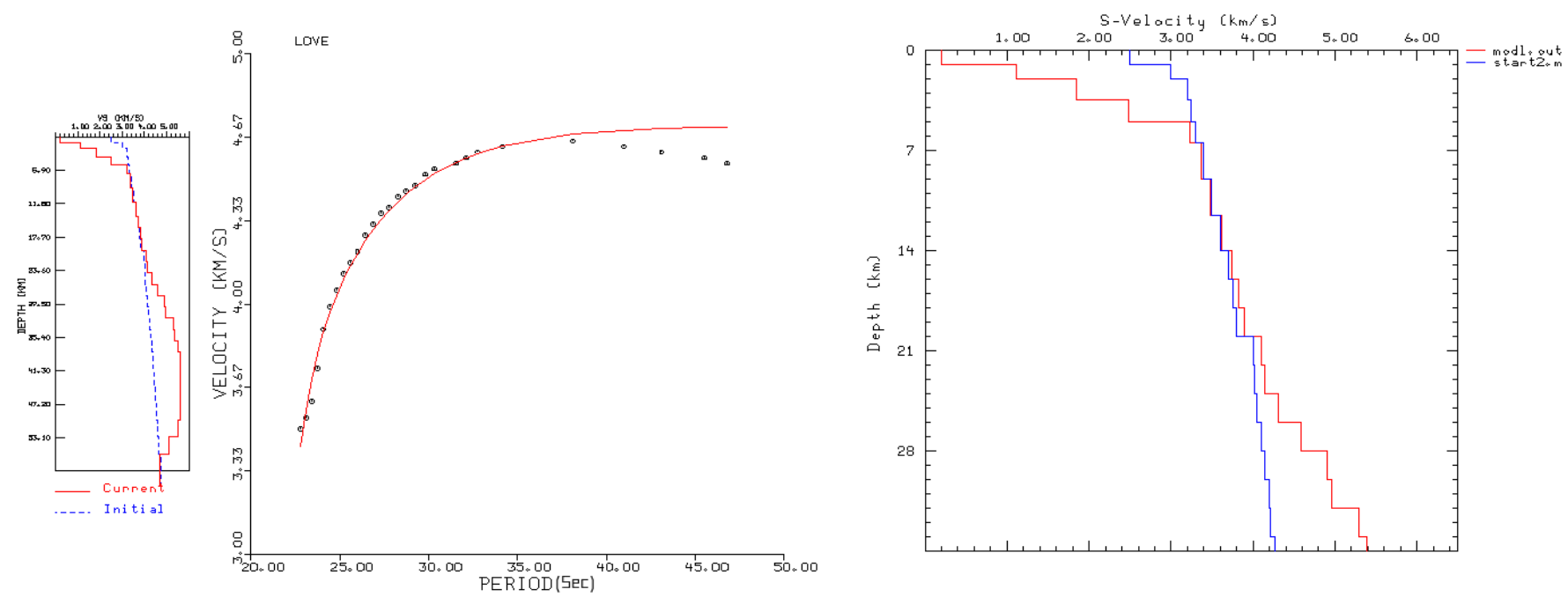

Figura 7: - Evento Norte da Califórnia. A esquerda, perfil e ajuste da curva de dispersão, ondas Love. O current é o resultado da inversão e initial é o modelo inicial. A direita, perfil da velocidade de onda S,ondas Love. O modl.out resultado da inversão e start2.mod é o modelo inicial. 

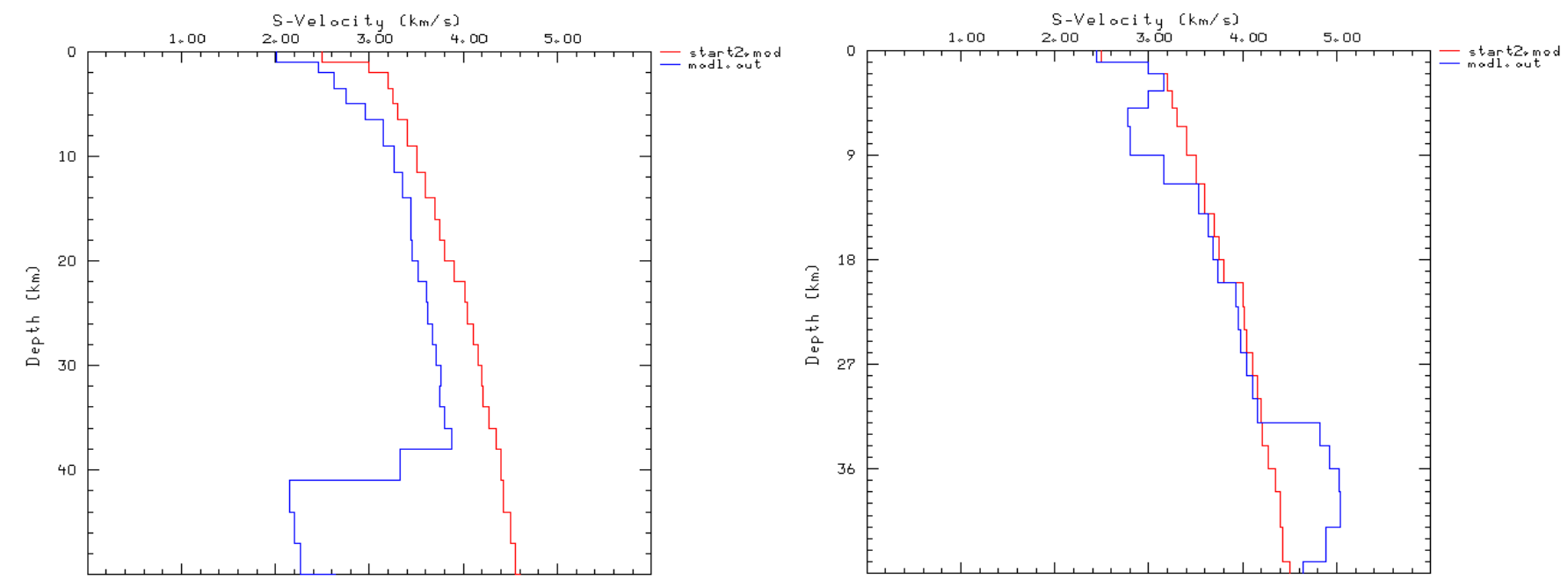

Figura 8: - A esquerda, Perfil da curva de dispersão SBBR-OCBR-RCBR, ondas Rayleigh. A direita, perfil da velocidade de onda S em SBBR-OCBR-PFBR, ondas Rayleigh, modl.out é o resultado da inversão e o start2.mod é o modelo inicial. 